ISSN 2075-9908 Историческая и социально-образовательная мысль. Том 7 №4, 2015 Historical and social educational ideas Tom 7 \#, 2015

УдК 37.013.2

DOI: 10.17748/2075-9908.2015.7.4.101-106

АНКВАБ Марина Фёдоровна, кандидат педагогических наук, доцент
ANKVAB Marina Fedorovna, Candidate of Pedagogical Science, Associate Professor

\section{NATIONAL PEDAGOGY AND ITS DEVELOPMENT IN THE REPUBLIC OF ABKHAZIA}

Статья посвящена резюмированному обзору понятия The article focuses on the summarized review of the con«народная педагогика» и термина «этнопедагогика». cept "national pedagogy" and the term "ethnoПриводятся отдельные суждения и толкования концеп- pedagogy". Some judgments and interpretations of the ции с точки зрения различных выдающихся ученых concept are given from the point of view of outstanding стран СНГ и регионов России, а также учителей, психо- scientists of the CIS countries and regions of Russia and логов, этнологов и историков Северного Кавказа и Аб- teachers, psychologists, ethnologists and historians of хазии. По убеждению автора, духовное богатство абха- the North Caucasus and Abkhazia. According to the auзов, запечатленное в его педагогике, предлагает образ- thor, the spiritual wealth of Abkhazians reflected in their цы для всестороннего, гармонического развития под- pedagogies offers models for comprehensive and harрастающего поколения, поэтому актуальность данного monious development of younger generation; therefore исследования обусловлена необходимостью правди- the relevance of this research is governed by the necessiвого и объективного освещения историкопедагогических процессов и назидательного опыта народа Абхазии с целью использования их для совершенствования современной системы образования в республике. В работе прослеживается момент оформления многовекового национального воспитания абхазов в активно исследуемую науку - народную педагогику. В заключение автором обозначены этапы еe исторического становления в республике, что является новым по сравнению с работами других исследователей, а также заложен фундамент для дальнейшего изучения методов воспитания абхазской народной педагогики, для реализации ее средств на современном пути просвещения.

Ключевые слова: Абхазия, абхазский, абхазский народ, абхазы, абхазская народная педагогика, Республика Абхазия, воспитание, обучение, система образования, народное просвещение, педагогика, этнопедагогика, абхазская этнопедагогика, этапы становления, педагогика Абхазии, система образования Абхазии

В ходе формирования концепции воспитания у множества представителей различных исторических эпох складывался безусловный дидактический опыт, который по прошествии определенного времени преобразовался в навык обучения и практику развития подрастающего поколения - народную педагогику. Результаты прогрессивного образования считаются дискурсивным следствием продолжительного становления педагогической мысли этноса. Духовно-культурное наследие народа Абхазии, нашедшее свое отражение в национальном просвещении, содержит примеры многогранного, гармоничного развития будущих преемников и модели формирования абсолютной личности. Таким образом, актуальность настоящего анализа продиктована потребностью истинного и справедливого толкования исторических процессов педагогики абхазов и практического навыка воспитания, с целью применения их в интересах улучшения деятельности нынешней концепции образования в республике.

Народная педагогика считается весьма обширной и значимой областью познаний, обладает фрундаментальными историко-культурными корнями и представляет собой важное доказательство необходимости исследования национальных традиций, обычаев, поведения и методов обучения подрастающего поколения в целом. На значимую утилитарную ценность этого явления указывали российские ученые, эксперты и педагоги: М.В. Ломоносов, В.Н. Татищев, Н.Я. Данилевский, В.Г. Белинский, А.И. Герцен, Н.Г. Чернышевский, писатели А.С. Пушкин, М.Ю. Лермонтов, Н.А. Некрасов, Л.Н. Толстой, проявляя серьезный интерес к социальной ценности различных аспектов национального образования и развития представителей всевозможных этносов [19, с. 493].

Стоит отметить, что основатель теории роста и становления индивида Я.А. Коменский уже в первых своих трудах упоминал народное просвещение и рассуждал о самобытном характере обучения. Всячески изучая жизненный уклад простого населения, он описывал историю, интересовался пословицами и поговорками как дидактическими единицами, проявлял повышенный интерес к назидательному потенциалу традиций и обычаев [10, с. 112]. 
К.Д. Ушинский полагал, что структура воспитания формируется посредством истории, устоями и бытом этноса, его духовным и культурным богатством. Известный педагог был убежден, что система способна существовать лишь при наличии этих концепций. «Любой народ едва ли сможет представлять интерес в науке, не насыщая ее истинами, верными для всех людей» [14, с. 161].

А.С. Макаренко заявлял о первостепенной значимости самобытного просвещения в обстоятельствах меняющейся действительности. Советский наставник и писатель тщательно изучал педагогическую практику коллективизма и внимательно следовал советам и мудрости передовых учителей, горячо преданных своему делу [11, с. 223].

Согласно суждениям В.А. Сухомлинского, наиболее значительной и сакральной функцией наставника является приобщение младших к умению ценить сотворенное поколениями предшественников, каждое из которых «добавило собственную капельку в тот океан, который воплощает собой культурное наследие» [13, с. 23].

Особый интерес к педагогике масс испытывал JІ.Н. Толстой и в качестве ее приемов всячески применял русский фольклор в обустроенной им школе для крестьянских детей.

Относительно недавно благодаря чувашскому деятелю науки Г.Н. Волкову, который утверждал, что «крайне весомый акцент на традиционную культуру воспитания, на педагогическую концепцию в современном мире обусловлен самой жизнью и закономерен; национальные дидактические принципы становятся фрактически основной предпосылкой к возрождению народа и восстановлению его естественных традиций» [5, с. 21], зародился термин «этнопедагогика». Учение стало отраслью науки просвещения, условия для возникновения которой появились лишь в середине прошлого века при постижении национального своеобразия целей, задач, методов, приемов и способов обучения, сакраментальных для определенной совокупности людей. В круг интересов этнопедагогики входит сопоставительный анализ назидательных особенностей, приемлемых для различных народов; изучение воздействия национального темперамента на развитие представителей всевозможных общностей. Она рассматривает воспитательный потенциал древних традиций в современном контексте и выясняет рациональность их использования в процессе становления личности. Сравнительное рассмотрение педагогических достижений в данной области дает возможность выявить наиболее целесообразные и объективные пути к реализации и теоретическому освоению следующих вопросов: семейное воспитание; традиции и обычаи, посредством которых происходит передача поколениями знаний, опыта и нравственных приоритетов; элементы фрольклора как средство умственного и эстетического обучения [4, с. 42], а также рассматриваются особенности физического, трудового закаливания, характерные для того или иного этноса.

Известные наставники - Н.К. Крупская, А.В. Луначарский, С.Т. Шацкий - в значительной степени придерживались достижений простых людей в пестовании молодежи. Изрядную лепту В усовершенствование науки этнопедагогики привнес и А.А. Потебня. Он рассматривал проблемы теории языкознания, а также фольклора, полагая, что «язык не является средством выражения законченной мысли». Иначе, не имело бы значения, на каких языках общаться, они были бы легко взаимозаменяемы. Однако это не так, и предназначение языка - не озвучивать заранее законченную мысль, а создавать ее. А.А. Потребня отмечал, что различные национальности имеют обыкновение формулировать мысли в речь особым, свойственным только им способом [12, с. 23-24].

Тем не менее, народная педагогика не была отдельной научной отраслью, а стала объектом изучения лишь в 50-х гг. ХХ в. И только вследствие усилий Я.И. Ханбикова, В.А. Афанасьева, А.Ф. Хантибидзе, А.А. Арутюнова, А.Ш. Пашимова, работавших над научным формулированием и структуризацией вопроса, она была организованна в отдельную сферу познания, проблемы которой были отображены в деятельности выдающихся учителей Северного Кавказа: Т.3. Басаевой, М.Б. Гуртуевой, М.А. Мамхеговой, Ш.А. Мирзоева, В.В. Смиренина, Э.М. Тамбиевой (Кабардино-Балкария), Х.Х. Хадикова, Е.Е. Хатаева (Северная Осетия), И.А. Шорова (Адыгея), 3.А. Якубова (Дагестан) и др. [9, с. 5] Как отмечает дагестанский ученный И.А. Агабалаев, «у представителей многонационального Дагестана этническая педагогика, многовековой процесс наставления младших поколений, имеет массу общего с другими кавказскими республиками, что объясняется общностью происхождения, исторических судеб, природногеографических, экономических, политических и культурных условий их жизни» [1, с. 6], а также доказывает состоятельность и достоверность проверенных разными этносами методов, целей и задач воспитания. Данный факт, на наш взгляд, во многом поможет пролить свет и дать точное определение явлению направленного фрормирования личности в условиях абхазского региона, становление изучения которого в настоящее время находится лишь на зачаточной стадии своего развития. 
ISSN 2075-9908 Историческая и социально-образовательная мысль. Том 7 №4, 2015 Historical and social educational ideas Tom 7 \#, 2015

Идеи и опыт абхазского народного просвещения упоминаются в различных трудах ученых Абхазии: В.А. Бигуаа, Р.К. Агрба, Б.Г. Тарба, В.Б. Кураскуа, О.Б. Шванба, С.Ю. Жвания, А.М. Касландзия и др. [2, с. 69]. В их исследованиях разрабатывались задачи объединения национального и межнационального воспитания, обсуждалось обучение детей на родном языке, идеи женского образования, приобщение к труду и фризической культуре. Несмотря на это, в настоящее время проблемы становления и методологии абхазской народной педагогики являются нерешенными.

Основной целью национального обучения абхазов было и остается личностное развитие и формирование человека согласно требованиям законов предков, традиций, обычаев и морально-этического понятия «апсуара». Это «доминирующее национальное понимание абхазов о своеобразии и независимости своей культуры, о приобретенных и передаваемых мудрых, гуманных исторических традиций и ценностей» [17, с. 161].

Для полноценного осуществления данной задачи необходима координация и налаживание двух синхронических аспектов - обучения и воспитания. Последний зародился наряду с образованием исторических предпосылок развития абхазского народа, а также реализовывался в различных процессах как социальной, так и семейной жизни, в том числе физической, трудовой и других жизненно важных видах деятельности. Этот этап характеризуется необходимостью передачи наличествующего многовекового достояния предыдущих поколений - будущим.

Воспитание - это универсальный феномен, интегрирующий заботу о ребенке, охрану его жизнедеятельности и состояния здоровья, осознанное оказание влияния другими людьми, направленное на привитие индивиду существенных умственных, нравственных, физических и эстетических качеств, которые пригодятся ему в жизни [8, с. 117]. Из этого следует, что передача знаний, наработанных веками, была и остается одной из самых важных задач как всего человечества, так и каждого индивида в отдельности. В ходе воспитания непрерывно происходит приобретение и усовершенствование частного навыка и умения в разнообразных жизненных сорерах, при этом значительную важность имеет общение со взрослыми, мудрыми людьми, свидетельством чего могут быть абхазские пословицы: «Беда и погибель грозит народу, у которого младшие не будут чтить старших», «Как ты чтишь родителей своих, так и тебя твои дети будут почитать», «Дерево с глубокими корнями засуха не страшит» [18]

Обучение подрастающего поколения у абхазов с давних пор расценивалось как естественный процесс осуществления определенной миссии по примеру предков, благоприятствующей самосохранению и формированию этноса. Согласно суждениям знаменитого абхазского историка, этнографа и литературоведа Ш.Д. Инал-ипа, еще в стародавние времена общество имело свои убеждения о пестовании детей, обладало педагогическими методами и приемами влияния на молодежь, чтобы направлять его развитие в правильное русло [7].

Создание семьи и появление детей является необходимостью и благодатью для каждого полноценного члена социума, а воспитание своего потомства в духе «апсуара» и забота о старших - это обязанность любого представителя абхазского народа. На самом деле реализация семьей репродуктивного предназначения сопряжена с исполнением ею и хозяйственноэкономической, образовательной, общественной и культурной функций. «В Абхазии заведено, что семья - это основа всех основ, зачаток здравой жизнедеятельности населения» [15, с. 59], а так как ее воспитательный потенциал едва ли возможно переоценить, то она и является началом всех начал для абхазской народной педагогики. Результаты сказанного были наиболее наглядно выражены в традиционных абхазских семьях с большим количеством детей. Здесь у каждого ребенка была огромная возможность для развития коммуникативных навыков, тесных родственных связей и взаимоотношений. В многодетных семьях отсутствовала почва для взращивания эгоизма, солипсизма и прочих антиобщественных черт. У старших братьев и сестер развивалось чувство ответственности к младшим, которые, в свою очередь, учились обязанностям перед старшими. Подростки помогали родителям, учились тем самым воспитанию, а дети возрастом поменьше им подражали.

Детей учили пониманию жизненных установок, нормам социального поведения, аккумулируемым на протяжении веков. Главной задачей воспитания, если судить по преданиям абхазов, является формирование многогранной личности, готовой к противостоянию всяческим насущным трудностям. Этот факт подтверждают творения абхазского фольклора, где главные персонажи отличаются выдающимися умственными способностями, физическими, нравственными и эстетическими характерными чертами. Идея роста духовного богатства народа посредством слаженной системы воспитания всеобъемлюще отображена в героическом сказании «Нартский эпос» [6]. Концепцию усовершенствованного процесса онтогенеза человека также можно проследить в абхазских пословицах и поговорках. В них, намерение воспитать молодежь в трудовом, физическом и умственном ключе очевидна. Значительная роль в перечисленных 
средствах устного творчества отводится цели пестования морально-нравственного, интеллектуального облика младших преемников, в духе любви к родине и человечности.

Со временем под влиянием социально-экономических процессов большие, насчитывающие порой до семидесяти человек семьи, в которых каждый трудился на общее благо, сменялись привычными современной Абхазии ячейками общества [16, с. 178]. Изучив множество источников о традициях и обычаях абхазов, данный этап можно назвать переломным в формировании абхазской народной педагогики. Если в многочисленном роду воспитанием детей занимается старшая женщина, умудренная жизненным опытом, а не мать, по обычаю избегания, то позже ситуация меняется в сторону более привычной для современного восприятия. Данные преобразования не завершились окончательно к периоду становления абхазской письменности в 60-е гг. XIX в., когда наступила эра образования в республике.

Третий этап, повлиявший на процесс развития абхазской народной педагогики, можно условно назвать «советским». В этот период набирает обороты коллективизм, пришедший в Абхазию с коммунистической властью. Советское образование во многом взяло на себя воспитательные функции и пыталось привить достойнные и характерные для того времени идеалы [3]. Тем не менее, предмет нашего исследования был ярко выражен, шел бок обок с общеобразовательной наукой, сохраняя устои и самобытность абхазов.

В 1945 г. систему образования в Абхазии признали неблагоприятной для «дальнейшего развития культуры народа». Безосновательно было утверждение о том, что родной язык оказывал негативное воздействие на приобретение детьми достоверных знаний. Следовательно, обучение в республике было переведено с абхазского языка на грузинский. «С 1946-1947 учебного года официально признанным языком преподавания в абхазских средних учебных заведениях является грузинский». В сфрере данных реформ пострадали многие учащиеся, не владеющие или слабо знакомые с установленным на тот момент языком просвещения. Большинство высококвалифицированных специалистов остались без работы. Упадком успеваемости и низким уровнем образования можно охарактеризовать этап, который длился до 1953 г., когда началось возрождение и реконструкция ряда абхазских школ - значимое событие для последующего становления народного образования в Абхазии и ее этнопедагогики в целом [3, с. 242].

Отдельным периодом следует отметить «post-soviet conflict», как тяжелое во всех отношениях время, страшный, «сложный моральный и психологический вызов», угроза существования всего народа [20, с. 38].

Сейчас, в век демократии, отечественное просвещение не сфокусировано на наставничестве, как в былые времена, и основной задачей институтов образования является только обучение, что на наш взгляд не совсем правильно. Нельзя перекладывать воспитание ребенка лишь на семью, которая, как мы выяснили, уже не строится по законам минувшего прошлого. Лишь в сотрудничестве родителей и школы (детского сада - вуза), основанного на принципах абхазской народной педагогики, можно достичь успеха в воздействии на современное подрастающее поколение.

Исходя из вышесказанного, мы сделали следующие выводы: народная педагогика - это комплекс и взаимосвязь мнений, точек зрения, суждений, понятий, знаний в сфере воспитания и обучения, нашедших свое отображение в творчестве, которое охватывает различные формы деятельности: ремесленничество, традиции, обычаи, обряды, празднования, фольклор, игры, национальные танцы, этнический рисунок, декоративно-прикладное искусство и т.п. Этнопедагогика рассматривает образование отдельных сообществ и определяет способы его применения в современном мире, накапливает и занимается изучением практики этнических групп, основывающейся на вековом, естественно развивающемся конгломерате национальных традиций; анализирует обучающую роль тех или иных педагогических явлений жизни населения и соотносит их с современными задачами воспитания.

Анализ различных аспектов быта и традиций абхазов, исторических материалов и архивных документов, этнологических, педагогических, фрилософских трудов и литературных произведений современных деятелей науки и авторов прошлых столетий позволил нам условно выделить этапы становления абхазского народного просвещения, что является новым и прежде не встречалось в работах других исследователей. Данная градация в значительной степени сможет пролить свет на изучение особенностей рассматриваемого вопроса:

1. Исторический процесс национального воспитания (возникший с зарождением самого этноса), главный фрактор коего воплощается в росте и развитии. Вместе с многовековым формированием абхазской цивилизации совершенствовался и принимал самобытные черты назидательный опыт, явившийся отражением социальных и межличностных взаимоотношений.

2. Этап появления письменности - 1862 г. (который в свою очередь имел отдельные фразы развития) положил начало современной системе образования. 
ISSN 2075-9908 Историческая и социально-образовательная мысль. Том 7 №4, 2015

Historical and social educational ideas Tom 7 \#4, 2015

3. Советский период знаменуется изрядными реформами в сфере пересмотра ценностей, воспитания и обучения.

4. Критическое время системы просвещения Абхазии (1945-1953).

5. Постсоветский период конфоликта и его последствия.

6. Обучение в эпоху современной демократии.

Следует отметить, что приведенные нами примеры семейного и общественного уклада послужат основой для дальнейшего вычленения особенностей методов и средств обучения абхазов, для перспективного внедрения национально-культурного компонента в систему просвещения республики, в попытке сохранить самобытность и способствовать прогрессивному развитию населения Абхазии.

Народная педагогика, безграничное отражение естественных навыков и умений в воспитании, некоего уровня педагогического мастерства, определенной ступени в духовном и историческом ходе преобразования, явилась зачатком возникновения и становления современной науки, известной нам как педагогика. Из года в год будут ставиться новые задачи и иели, будут возникать новые вопросы и будут вестись мучительные поиски ответов на них, поэтому никогда не утихнут споры о методах воспитания и обучения.

\section{БИБЛИОГРАФИЧЕСКИЕ ССЫЛКИ}

1. Агабалаев И.А. Этнокультура как компонент воспитания молодежи в Дагестане // Вестник социальнопедагогического института. - 2014. - № 1 (9). - С. 3-7.

2. Анкваб М.Ф. Абхазская народная педагогика // Личность, семья и общество: вопросы педагогики и психологии. - 2014. - № 47. - С. $66-70$, с. 69

3. Ачугба Т.А. Этническая история абхазов XIX-XX вв. Этнополитические и миграционные аспекты. - Сухум, 2010. - $356 \mathrm{c}$.

4. Битарова А.Т. Этикет горских народов Северного Кавказа и его влияние на воспитание подрастающего поколения: Дис... канд. пед. наук: 13.00.01: Владикавказ, 2002. - 170 с.

5. Волков Г.Н. Этнопедагогика. / Текст. Г.Н. Волков. - М.: Академия, 1999. -168 с.

6. Джапуа 3.Д. Нартский эпос у зарубежных абхазов // Всероссийские Миллеровские чтения. - 2012. - Т. 3. - С. 224-238.

7. Инал-ипа Ш.Д. Что рассказывают абхазы о древнейшем населении Абхазии и своем происхождении (материалы с комментариями) / Опубликовано: Абхазоведение. Язык. Фольклор. Литература. // выпуск. - Сухум, 2006. - C. 193-255.

8. Кикеева С.А. Этнопедагогика в воспитании детей дошкольного возраста / В сборнике: Этнопедагогическая пансофия академика Г.Н. Волкова как фрактор социальной безопасности народов в условиях глобализации (VI Волковские чтения) / материалы Международной научно-практической конференции, посвященной 85-летию со дня рождения академика РАО Г.Н. Волкова. 2012. - С. 116-118.

9. Климатова В.В. Идеи и опыт трудового воспитания в народной педагогике Северного Кавказа : Дис... канд. пед. наук: 13.00.01: Владикавказ, 2004. - 151 с.

10. Коменский А.Я. Великая дидактика / Избранные педагогические сочинения. - М., 1955. - С. 45-46.

11. Копёнкина Л.В. Видные деятели культуры и общественной мысли XX века. - М., 1997. - 432 с.

12. Потебня А.А. Сочинения. - М., 1945. - 321 с.

13. Сухомлинский В.А. Поучение детям. - М., 1987. - 321 с.

14. Ущинский К.Д. О народности в общественном воспитании / Педагогические сочинения: В 6 т. - М.-П., 1988. T.2. - С. 161.

15. Хашба А.Ш. Современная абхазская сельская семья. В сборнике: Этническая экология: народы и их культура / Дубова Н.А., Соловьева Л.Т. - Москва, 2008. - С. 58-70.

16. Цугба М.Э. Права и обязанности родителей и детей по адатам абхазов и по российскому гражданскому законодательству (XIX - нач. XX вв.): сравнительно-правовая характеристика // Черные дыры в Российском законодательстве. - 2010. - № 2. - С. 177-179.

17. Читашева Р.Г. Абхазская этнокультурная система Апсуара-Абхазство (Эволюция, современное состояние и проблемы) : Дис... канд. ист. наук: 07.00.07: Нальчик, 2005. - 201 с.

18. Шамба О.Б. Пословицы абхазского народа. - Сухум: АГУ, 1994. - 78 с.

19. Юдина О.И. Этнопедагогика как аксиологический ресурс образования // Фундаментальные исследования. 2014. - № 8-2. - С. 492-495.

20. Yazkova A. Conflicts in the Post-Soviet Space: an Abkhazian Case-Study // The Caucasus \& Globalization. - 2012. T. 6. - № 1. - Pp. 32-39.

\section{REFERENCES:}

1. Agabalayev I.A. Ethnoculture as a component of youth upbringing in Dagestan [Etnokultura kak komponent vospitaniya molodezhi v Dagestane]. Vestnik sotsialno-pedagogicheskogo instituta - Bulletin of social teacher training college, 2014. № 1 (9). Pp. 3-7. (in Russian) 
2. Ankvab M.F. Abkhazian national pedagogy [Abhazskaya narodnaya pedagogika]. Lichnost, semya $i$ obschestvo: voprosyi pedagogiki i psihologii - Personality, family and society: questions of pedagogics and psychology, 2014. № 47. Pp. 66-70. (in Russian)

3. Achugba T.A. Ethnic history of Abkhazians of the XIX-XX centuries. Ethnopolitical and migratory aspects [Etnicheskaya istoriya abhazov XIX-XX vv. Etnopoliticheskie i migratsionnye aspekty]. Sukhum, 2010.356 pages. (in Russian)

4. Bitarova A.T. Etiquette of the mountain people of the North Caucasus and its influence on education of younger generation [Etiket gorskih narodov Severnogo Kavkaza i ego vliyanie na vospitanie podrastayuschego pokoleniya]: Candidate dissertation on pedagogical sciences: 13.00.01: Vladikavkaz, 2002170 pages. (in Russian)

5. Volkov G.N. Ethnopedagogy [Etnopedagogika]. Text. G. N. Volkov. Moskva: Publishing center "Academia", 1999. 168 pages. (in Russian)

6. Dzhapua Z.D. The Narts epos at foreign Abkhazians [Nartskiy epos u zarubezhnykh abkhazov]. All-Russian Miller readings - Vserossiyskie Millerovskie chteniya. 2012. Volume 3. Pp. 224-238. (in Russian)

7. Inal-ipa Sh.D. What Abkhazians tell about the most ancient population of Abkhazia and the origin (materials with comments) [Chto rasskazyivayut abhazy o drevneyshem naselenii Abkhazii i svoem proishozhdenii (materialy s kommentariyami)]. Published: Abkhazovedeniye. Language. Folklore. Literature. II issue. Sukhum, 2006. Pp. 193255. (in Russian)

8. Kikeeva S.A. Ethnopedagogy in education of children of preschool age [Etnopedagogika v vospitanii detey doshkolnogo vozrasta] In the collection: An ethnopedagogical pansofiya of the academician G. N. Volkov as a factor of social safety of the people in the conditions of globalization (the VI Volkovsky readings). Materials of the International scientific and practical conference devoted to the 85 anniversary since the birth of the academician of RJSC G.N. Volkov. 2012. Pp. 116-118. (in Russian)

9. Klimatova V.V. Ideas and experience of labour education in national pedagogy of the North Caucasus [Idei i opyt trudovogo vospitaniya $\mathbf{v}$ narodnoy pedagogike Severnogo Kavkaza]: Dissertation on pedagogical sciences: 13.00.01: Vladikavkaz, 2004151 pages.

10. Kamenskiy A.Ya. Great didactics [Velikaya didaktika] Chosen pedagogical compositions - Izbrannyie pedagogicheskie sochineniya. Moscva, 1955. Pp. 45-46. (in Russian)

11. Kopenkina L.V. Eminent persons of culture and social thought of the XX century [Vidnye deyateli kultury i obschestvennoy mysli XX veka]. Moscva, 1997. 432 pages. (in Russian)

12. Potebnya A.A. Compositions [Sochineniya]. Moscva, 1945. 321 pages. (in Russian)

13. Sukhomlinsky V.A. Exhortation to children [Pouchenie detyam]. Moscva, 1987. 321 pages. (in Russian)

14. Ushinsky K.D. About a nationality in public education [O narodnosti v obschestvennom vospitanii]. Pedagogical compositions - Pedagogicheskie sochineniya: In 6 volumes. Moscva, 1988. Volume 2. 161 pages. (in Russian)

15. Hashba A.Sh. Modern Abkhazian rural family [Sovremennaya abhazskaya selskaya semya]. In the collection: Ethnic ecology: people and their culture - V sbornike: Etnicheskaya ekologiya: narodyi $i$ ih kultura. Dubov N.A., Solovyova L.T. Moscow, 2008. Pp. 58-70. (in Russian)

16. Tsugba M.E. The rights and obligations of parents and children in customs of Abkhazians and by the Russian civil legislation (to XIX - the head of the XX centuries): comparative and legal characteristic [Prava i obyazannosti roditeley i detey po adatam abhazov i po rossijskomu grazhdanskomu zakonodatelstvu (XIX - nach. XX vv.): sravnitelno-pravovaya kharakteristika]. Black holes in the Russian legislation - Chernyie dyiryi v Rossiyskom zakonodatelstve. 2010. № 2. Pp. 177-179. (in Russian)

17. Chitasheva R.G. Abkhazian ethnocultural system of Apsuara - Abkhazstvo (Evolution, current state and problems) [Abkhazskaya etnokulturnaya sistema Apsuara-Abhazstvo (Evolyutsiya, sovremennoe sostoyanie i problemy)]: Dissertation on historical sciences: 07.00.07: Nalchik, 2005201 pages. (in Russian)

18. Shamba O.B. Proverbs of the Abkhazian people [Poslovitsy abkhazskogo naroda]. Sukhum: Abkhazian State University, 1994. 78 pages. (in Russian)

19. Yudina O.I. Ethnopedagogy as axiological resource of education [Etnopedagogika kak aksiologicheskij resurs obrazovaniya]. Basic researches - Fundamentalnyie issledovaniya. 2014. № 8-2. Pp. 492-495. (in Russian)

20. Yazkova A. Conflicts in the Post-Soviet Space: an Abkhazian Case-Study. The Caucasus \& Globalization. 2012. T. 6. № 1. Pp. 32-39. (in English)

\section{Информация об авторе}

Анкваб Марина Фёдоровна, кандидат педагогических наук, доцент кафредры иностранных языков, Абхазский государственный университет (384904, Республика Абхазия, г. Сухум, ул. Университетская 1), Сухум, Республика Абхазия ankvab.marina@yandex.ru

\section{Information about the author}

Ankvab Marina Fedorovna, Candidate of Pedagogical Science, Associate Professor, Chair of Foreign Languages, Abkhazian State University. (384904, the Republic of Abkhazia, Sukhum, Universitetskaya street 1), Sukhum city, Republic of Abkhazia ankvab.marina@yandex.ru 